\title{
Removal of methyl orange by activated carbon modified by silver nanoparticles
}

\author{
Jolly Pal · Manas Kanti Deb · Dhananjay Kumar Deshmukh • \\ Devsharan Verma
}

Received: 19 July 2012/ Accepted: 28 January 2013/Published online: 14 February 2013

(C) The Author(s) 2013. This article is published with open access at Springerlink.com

\begin{abstract}
In this work, the removal of methyl orange (MO) dye by adsorption on silver nanoparticles (AgNPs) coated activated carbon (AC) has been studied. The effect of various process parameters has been investigated by the column adsorption technique. Equilibrium adsorption data of MO were carried out at room temperature. Using AgNPs-coated AC, $72.5 \%$ of MO was removed, whereas only $50.0 \%$ when using AC after reacting for $16 \mathrm{~h}$ with an initial MO concentration of $2 \mathrm{mg} / \mathrm{L}(\mathrm{pH}=7)$. The equilibrium time is independent of the initial dye concentration and the percentage removal of MO increased with increase in contact time. The adsorption data were analyzed using adsorption isotherm. The characteristic parameters for isotherm and related correlation coefficients were determined from graphs of their linear equations. Kinetic studies showed that the adsorption of MO followed pseudosecond-order kinetics. AgNPs-coated AC is found to be suitable adsorbent for the adsorption of MO. Desorption studies were made to elucidate recovery of the adsorbate and adsorbent for the economic competitiveness of the removal system. The AgNPs-coated AC was successfully recycled for 10 successive adsorption-desorption cycles indicating its high reusability.
\end{abstract}

Keywords Silver nanoparticles - Activated carbon · Microwave irradiation - Methyl orange .

Polyvinylpyrrolidone

\footnotetext{
J. Pal · M. K. Deb $(\bowtie) \cdot$ D. K. Deshmukh · D. Verma

School of Studies in Chemistry, Pt. Ravishankar Shukla

University, Raipur 492 010, India

e-mail: debmanas@yahoo.com

J. Pal

e-mail: jollypa108@yahoo.co.in
}

\section{Introduction}

Textile industries have shown a significant increase in the use of synthetic complex organic dyes as colouring materials (Talarposhti et al. 2001). Dye is carcinogenic, affects reproductive organs and develops toxicity and neurotoxicity (Lakshmi 1987). Therefore, the dyes are to be necessarily removed from water and wastewater. Methyl orange (MO) is thought to be toxic if swallowed or inhaled and avoid skin contact with the solution or the solid. The structure of MO is demonstrated in Fig. 1. Different processes for colour removal typically include physical, chemical and biological schemes. Some processes such as electrochemical techniques and ion pair extractions are relatively new for textile waste treatment, while others have been used in the industry for a long time. Adsorption has been found to be superior than other techniques for water reuse in terms of initial cost, simplicity of design, use of operation and insensitivity to toxic substances ( $\mathrm{Pal}$ and Deb 2012a, b, c; Meshko et al. 2001). Adsorption has been used extensively in industrial process for separation and purification. The removal of coloured and colourless organic pollutants from industrial wastewater is considered as an important application of adsorption processes (Al-qodah 2000). Adsorption processes have been reported as low-cost techniques for the treatment of organic pollutants present in water (Bajpai et al. 2000, 2004; Shah et al. 2012; Chowdhury and Saha 2012; Djebbar et al. 2012; Belhachemi and Addoun 2011). Activated carbon (AC) is the most common adsorbent for adsorption process due to its effectiveness and versatility. AC is usually obtained from materials with high carbon content and possesses a great adsorption capacity, which is mainly determined by their porous structure. AC is carbonaceous material of highly developed porous structure and highly specific surface 


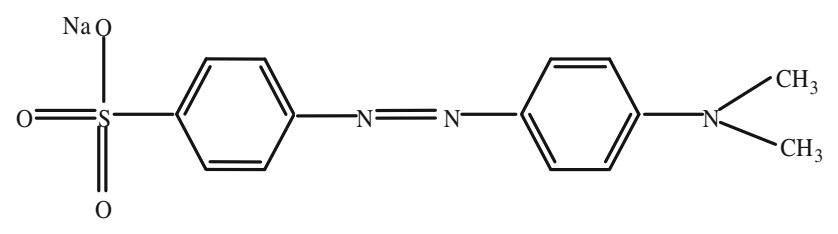

$\left[\left(\mathrm{CH}_{3}\right)_{2} \mathrm{NC}_{6} \mathrm{H}_{4}: \mathrm{NC}_{6} \mathrm{H}_{4} \mathrm{SO}_{3} \mathrm{Na}\right]$

Fig. 1 Chemical structures of MO

area. Properties of AC such as their surface area, micro porous structure and surface chemistry can be tailored, making them versatile materials for a range of separation applications (Banasa et al. 1988). These applications include the removal of contaminants from water and gas streams, and as catalyst support (Banasa et al. 1988). AC is quite expensive and the higher the quality the greater the cost. Both chemical and thermal regeneration of spent carbon is expensive, impractical on a large scale and produces additional effluent and results in considerable loss of the adsorbent (Aksu 2005). A porous carbon can be coated with a biocompatible polymer to give a smooth and permeable coat without blocking the pores. Polyvinylpyrrolidone (PVP) is soluble in water and other polar solvents. In solution, it has excellent wetting properties and readily forms films. This makes it good as a coating or an additive to coating over porous carbon. PVP is also used as a binder and complexation agent in agro applications such as crop protection, seed treatment and coating. Studies have been carried out aiming at developing more effective and selective adsorbent materials, which are abundant in nature, requiring little processing to decrease cost (Reddad et al. 2002). Phenomenological adsorption was generally described by a graphic representation of the distribution ratios of adsorbate adsorbed per unit mass of the adsorbent and the concentration of the unabsorbed adsorbate at constant temperature. This graphic representation is known as the adsorption isotherm. Several types of adsorption isotherms (Chatterjee et al. 2010; Pavan et al. 2008) have been reported in the literature, but the most widely used are the Freundlich and the Langmuir isotherms (Nagda and Ghole 2009; Chen and Zhao 2009).

Nanotechnology (Klefenz 2004) refers broadly to manipulating matter at the atomic or molecular scale and using materials and structures with nanosized dimension, usually ranging from 1 to 100 nanometres (nm). Nanotechnology is quickly developing in various fields like environmental and medical field. To meet diverse requirements, many efforts have been made on the nanoengineering of particle surface to tune the bulk properties, tailor the surface properties (e.g., charge density, functionality, reactivity, biocompatibility, stability, and dispersibility), produce hollow nanostructures materials, and create multifunctional composite nanoparticles (Zhang and Wang 2007). Binding capacity of noble metal nanoparticles with dyes are more when compared to other nanoparticles. Novel metal crystallites such as silver and gold provide a more interesting research field due to their close lying conduction and valence bands in which electrons move freely. The free electrons give rise to a surface plasmon absorption band which depends on both the particle size and chemical surrounding. The stabilizers such as surfactants and ionic polymers cannot be easily removed from the surfaces of the formed silver colloids, which unavoidably affect the physiochemical properties of the resulting nanoparticles. The most widely used substances for the stabilization of metal nanoparticles are ligands and polymers, specially natural or synthetic polymers with a certain affinity towards metals, which are soluble in suitable solvents (Hirai et al. 1985). The AC is an efficient adsorbent for removal of many chemical species (Mohammadi et al. 2011; Belhachemi and Addoun 2011; Chen et al. 2010; Mall et al. 2005; Meshko et al. 2001), however, its reusability is poor due to the loss during desorption. Hence, the main objective of this investigation was to examine adsorption characteristic for $\mathrm{MO}$ on modified $\mathrm{AC}$ by silver nanoparticles (AgNPs) coating on it. The effects of such factors as initial concentration, contact time and $\mathrm{pH}$ along with adsorption kinetics and desorption were also studied.

\section{Materials and methods}

\section{Materials}

All chemicals and reagents used were of analytical grade (Molychem/Himedia/Merck). All aqueous solutions were prepared in triple distilled water. $1.0 \times 10^{-4} \mathrm{~mol} / \mathrm{L}$ silver nitrate $\left(\mathrm{AgNO}_{3}\right), 0.5 \mathrm{~mol} / \mathrm{L}$ glucose, $1 \% \mathrm{PVP}$ and different ppm MO solution were used.

\section{Apparatus}

The apparatus used a Samsung CE2877 domestic microwave oven $(850 \mathrm{~W}$, Samsung India Electronics Ltd. New Delhi, India) was employed for irradiating solutions. The particle size and morphology of the AgNPs were characterized by (Morgagni 268D) transmission electron microscope (TEM). Absorbance was measured with UV-visible (Perkin-Elmer Lambda20) spectrophotometer. The XRD measurements were carried out using (Bruker D8 Advance) $\mathrm{X}$-ray diffractometer.

Preparation of silver nanoparticles

The reaction solutions were prepared by dissolving in triple distilled water $0.5 \mathrm{~mol} / \mathrm{L}$ glucose, $1.0 \times 10^{-4} \mathrm{~mol} / \mathrm{L}$ 
$\mathrm{AgNO}_{3}$ and $1 \%$ PVP in a $50 \mathrm{ml}$ Pyrex flask to obtain a homogeneous reaction mixture and flask was placed on the turntable of the microwave oven. The mixture was irradiated at a power of $300 \mathrm{w}$ for the duration of $4 \mathrm{~min}$ discontinuously to prevent an increase of pressure. After irradiation, the dilute colloidal solutions with pale yellow colours obtained were cooled at room temperature for further characterization.

Innovation of adsorbent

Initially, coals were nearby collected, slice into small round shape $\left(10 \mathrm{~mm}\right.$ diameter), washed, and dried $\left(50{ }^{\circ} \mathrm{C}\right)$ on hot plate. Adequate amounts of little pieces of $\mathrm{AC}$ were dipped into a colloidal solution of the prepared AgNPs capped with PVP, in a glass beaker $(250 \mathrm{ml})$. The beaker was kept on a hob and the substance was heated gently at $50{ }^{\circ} \mathrm{C}$ till dryness to remove the moisture from the substance. The PVP gives a polymeric support to fasten AgNPs over the surface of AC. The prepared adsorbent was taken for adsorption studies.

\section{Adsorption studies}

Adsorption isotherms describe the equilibrium relationship between bulk activity of adsorbate in solution and the moles adsorbed on the surface, at constant temperature. The MO was freshly prepared in ppm solution in triple distilled water. Adsorption experiment was conducted in which aliquots of MO solution with known concentrations were introduced into column containing accurately weighed amount of adsorbent. The adsorption of MO by AgNPs-coated AC was investigated in aqueous solutions at room temperature. To determine the equilibrium adsorption capacity of the MO by AgNPs-coated AC $100 \mathrm{ml}$ of adsorbate solution of several concentrations was placed in a column and adsorbent was added. The flask was sealed with a stopper and rest for $16 \mathrm{~h}$ at room temperature. After $16 \mathrm{~h}$ the adsorbate equilibrium concentration was measured using a UV-visible spectrophotometer at $460 \mathrm{~nm}$. MO concentration was determined as maximum absorbance $\left(\lambda_{\max }\right)$, using a UV-visible spectrophotometer. The diagrammatic representation of adsorption isotherm is shown in Fig. 2.

Effect of various process parameters on the extent of removal of MO was studies. The data were analyzed statistically and interpreted. Percentage removal has been calculated using the following equations:

Percentage removal $=100\left(C_{\mathrm{i}}-C_{\mathrm{e}}\right) / C_{\mathrm{i}}$

where, $C_{\mathrm{i}}$ and $C_{\mathrm{e}}$ are initial and equilibrium (final) concentration of dyes (in $\mathrm{mg} / \mathrm{L}$ ), respectively and $m$ is the mass of adsorbent in $\mathrm{g} / \mathrm{L}$. The data were analysed statistically and interpreted. The data have been modelled with

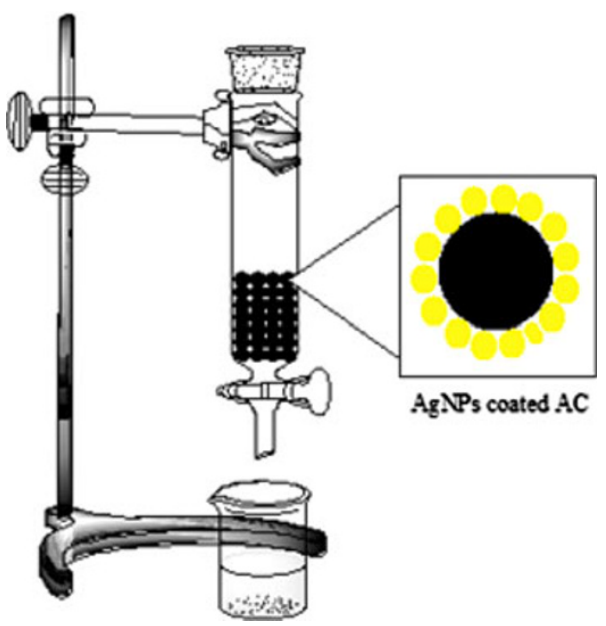

Fig. 2 Diagrammatic representation of adsorption isotherm

adsorption isotherms, namely Freundlich isotherm and Langmuir isotherm.

The adsorption characteristics for wide range of adsorbate concentration are mostly described by adsorption isotherm (Freundlich and Langmuir), which relates the equilibrium adsorbate concentration in the bulk and the uptake of adsorbate on the adsorbent surface. Freundlich isotherm (Lata et al. 2008) is presented by the following relation:

$\ln Q_{\mathrm{e}}=\ln K_{\mathrm{F}}+\frac{1}{n} \ln C_{\mathrm{e}}$

where, $K_{\mathrm{F}}$ and $n$ are Freundlich constant, a characteristic of the system indicating the adsorption capacity and adsorption intensity, respectively.

The Langmuir isotherm (Liu et al. 2012) is valid for monolayer adsorption onto a surface containing a finite number of identical sites

$\frac{C_{\mathrm{e}}}{Q_{\mathrm{e}}}=\frac{b}{Q_{\mathrm{o}}}+\frac{C_{\mathrm{e}}}{Q_{\mathrm{o}}}$

where, $C_{\mathrm{e}}$ is the equilibrium dye concentration in the solution $(\mathrm{mg} / \mathrm{L}), Q_{\mathrm{e}}$ is the equilibrium dye concentration on the adsorbent $(\mathrm{mg} / \mathrm{g}), Q_{0}$ is the maximum adsorption capacity of the dye (forming a monolayer) per unit weight of adsorbent $(\mathrm{mg} / \mathrm{g})$, and $b$ is a constant related to the affinity of the binding sites $(\mathrm{L} / \mathrm{mg})$.

The essential characteristics of the Langmuir isotherm can be expressed by a separation factor $R_{\mathrm{L}}$ (Mall et al. 2005), which is defined in the following equation:

$R_{\mathrm{L}}=\frac{1}{1+b C_{0}}$

the $R_{\mathrm{L}}$ value shows the nature of the adsorption process to be unfavourable $\left(R_{\mathrm{L}}>1\right)$, linear $\left(R_{\mathrm{L}}=1\right)$, favourable $\left(0<R_{\mathrm{L}}<1\right)$, or irreversible $\left(R_{\mathrm{L}}=0\right)$. 
Fig. 3 a UV-visible spectrum of the synthesized AgNPs, b TEM image of the AgNPs prepared employing glucose as reducing agent and PVP as stabilizing agent $(300 \mathrm{~W} ; 4 \mathrm{~min}$ irradiation). Magnification:

$\times 13,000$; resolution:

$1,376 \times 1,032 \times 16$; image intensity: gray value; accelerating voltage: $70 \mathrm{kV}$; microscope: morgagni 268 ; camera type: Keen View FW, c XRD of (i) AC (ii) AgNPscoated AC

Fig. 4 a Effect of initial concentration, $\mathbf{b}$ effect of contact time, $\mathbf{c}$ effect of $\mathrm{pH}$ on the removal of MO by AgNPscoated $\mathrm{AC}$ at room temperature
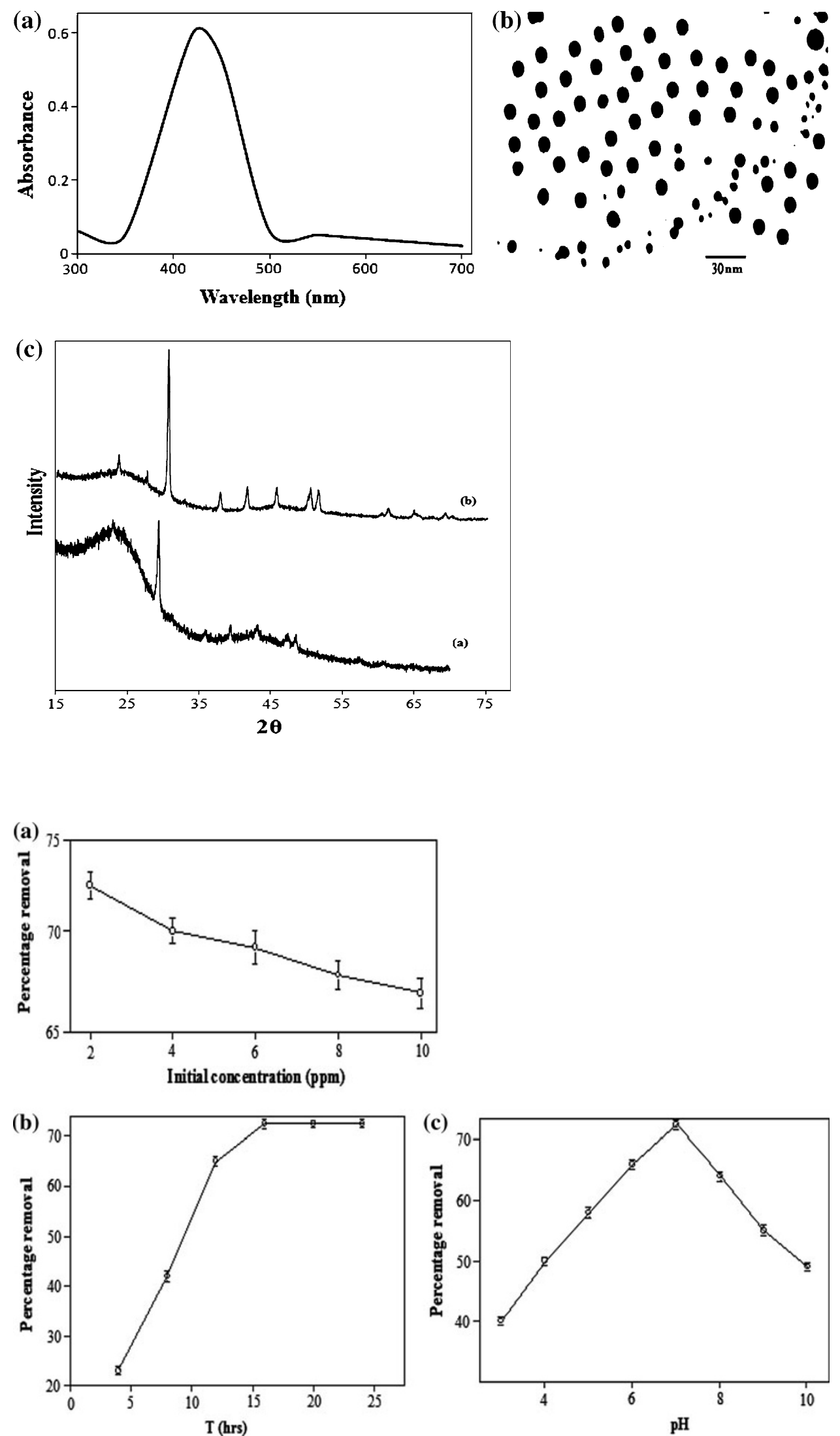
Fig. 5 a Freundlich isotherm plot, b Langmuir isotherm plot for adsorption of MO on AgNPs-coated AC at room temperature

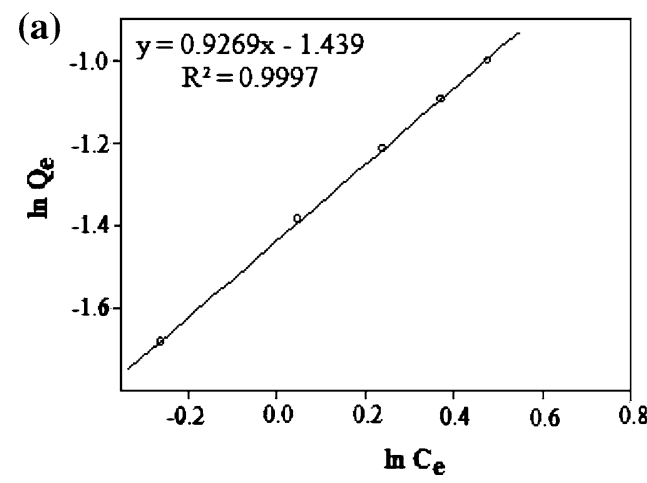

Table 1 Adsorption isotherm and kinetics data for removal of MO by AgNPs-coated AC at room temperature

\begin{tabular}{|c|c|c|c|c|c|c|c|c|c|}
\hline \multirow[t]{2}{*}{ Adsorbent } & \multicolumn{3}{|c|}{ Freundlich constants } & \multicolumn{4}{|c|}{ Langmuir constants } & \multicolumn{2}{|c|}{ Pseudo-second-order } \\
\hline & $K_{\mathrm{F}}(\mathrm{mg} / \mathrm{g})$ & $n$ & $R^{2}$ & $Q_{\mathrm{o}}(\mathrm{mg} / \mathrm{g})$ & $b(\mathrm{~L} / \mathrm{mg})$ & $R^{2}$ & $R_{\mathrm{L}}$ & $k_{2}(\mathrm{~g} / \mathrm{mg} / \mathrm{h})$ & $R^{2}$ \\
\hline AgNPs-coated AC & $27.48 \pm 0.55$ & 1.08 & 0.99 & $0.69 \pm 0.55$ & 0.06 & 0.99 & 0.90 & $1.91 \pm 0.60$ & 0.88 \\
\hline
\end{tabular}

$K_{F}$ adsorption capacity, $n$ adsorption intensity, $R^{2}$ correlation coefficients, $Q_{0}$ maximum adsorption capacity of the dye (forming a monolayer) per unit weight of adsorbent $(\mathrm{mg} / \mathrm{g}), b$ constant related to the affinity of the binding sites $(\mathrm{L} / \mathrm{mg}) R_{L}$ nature of the adsorption process, $k_{2}$ pseudosecond-order rate constant

\section{Desorption studies}

Desorption of MO from adsorbent surface was carried as follows: after adsorption experiments with $\mathrm{MO}$ under optimum conditions, the AgNPs-coated AC was separated and washed with $0.05 \mathrm{~N} \mathrm{HNO}_{3}$ to remove adsorbed MO. The colour intensity of the MO desorbed was measured at $460 \mathrm{~nm}$.

\section{Percentage Desorption}

$$
=\frac{\text { amount of dye liberated by acid }}{\text { amount of dye adsorbed on adsorbent }} \times 100
$$

\section{Results and discussion}

Formation of silver nanoparticles

It is interesting to find that AgNPs can be synthesized with $\mathrm{PVP}$, glucose and $\mathrm{AgNO}_{3}$ promoted by microwave irradiation. Figure $3 \mathrm{a}$ shows the UV-visible spectrum of the prepared AgNPs in water. The colloidal silver solution thus formed exhibits a strong absorption at $420 \mathrm{~nm}$. The yellow colour of the colloidal silver sample provides clear evidence for the formation of AgNPs. According to Mie's theory (Mie 1908), small spherical nanocrystals should exhibit a single surface plasmon band, whereas anisotropic particles should exhibit two or three bands, depending on their shape. Absorption spectra of larger metal colloidal dispersions can exhibit broad or additional bands in the UV-visible range due to the excitation of plasma resonances or quadrupole and higher multipole plasmon excitation.
Transmission electron microscope image was further used to characterize AgNPs. Figure $3 b$ shows the TEM image. The photograph shows that most of the particles are nearly spherical. AgNPs thus formed were free from flocculation or aggregation for several months, suggesting that the polymer serves as a very effective protective agent for AgNPs. TEM image shows the average size of AgNPs to be $11 \mathrm{~nm}$. The specific surface area of adsorbent is $3.14 \mathrm{~cm}^{2}$.

The XRD patterns of AC and AgNPs-coated AC, shown in Fig. 3c, were also used to confirm the existence of AgNPs. AC shows peaks at $2 \theta=24.7^{\circ}, 29.5^{\circ}, 39.5^{\circ}$, $43.3^{\circ}, 47.4^{\circ}$ and $48.6^{\circ}$. After coating of PVP-supported AgNPs over AC a significant change in XRD pattern was observed. In the AgNPs-coated AC sample new peaks

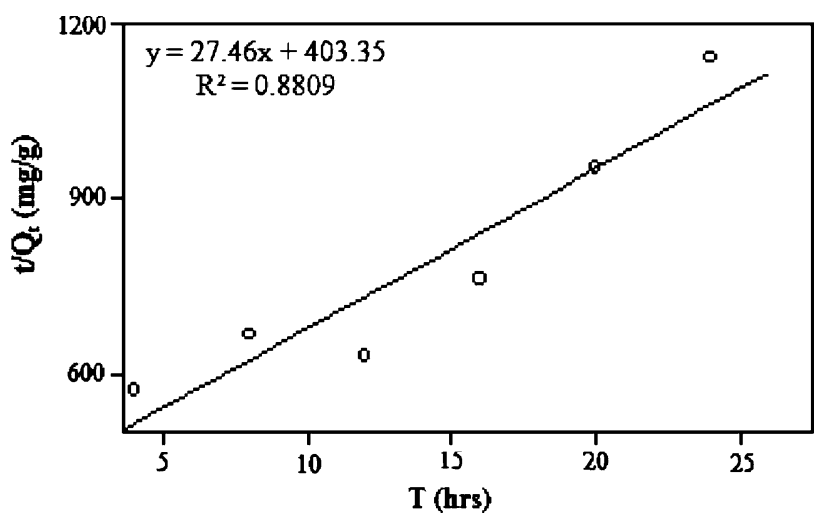

Fig. 6 Pseudo-second-order kinetic plot for the removal of MO by AgNPs-coated AC 
appeared at $2 \theta=23.0^{\circ}, 26.6^{\circ}, 29.4^{\circ}, 36.0^{\circ}, 39.4^{\circ}, 43.2^{\circ}$, $47.4^{\circ}, 48.4^{\circ}, 57.4^{\circ}, 60.6^{\circ}$ and $64.6^{\circ}$. The crystallinity of $\mathrm{AC}$ was apparently lower than that of the AgNPs-coated AC. The results indicate that the crystallinity of PVPsupported AgNPs-coated AC was increased because of the formation of $\mathrm{Ag}$ nanoparticles.

\section{Effect of initial MO concentration}

The effect of initial concentration on the percentage removal of MO is shown in Fig. 4a. The percentage removal decreased with the increase in initial concentration of MO. This may probably be due to the limited number of available active sites on the surface of AgNPs-coated AC to accommodate higher concentration of MO.

\section{Effect of contact time}

Effect of contact time on the percentage removal of MO is shown in Fig. 4b. The percentage removal of MO increased with an increase in contact time and reached equilibrium after $16 \mathrm{~h}$ for the initial $\mathrm{MO}$ concentrations of 2, 4, 6, 8 and $10 \mathrm{ppm}$ MO used in this study. The equilibrium time is independent of initial dye concentration. At the initial stage, the rate of removal of MO was higher, due to the availability of more than required number of active sites on the surface of carbons and becomes slower at the later stages of contact time, due to the decreased or lesser number of active sites (Toshima and Yonezawa 1998).

\section{Effect of $\mathrm{pH}$}

Effect of $\mathrm{pH}$ on the removal of MO by AgNPs-coated AC is shown in Fig. 4c. The percentage removal increased from $40.0 \pm 0.7$ to $72.5 \pm 0.8$, when $\mathrm{pH}$ was increased from 3 to 7 and the removal decreased thereafter. Colour removal due to $\mathrm{pH}$ change alone may be due to the structural changes being affected in the dye-molecules (Kannan and Karrupasamy 1998).

\section{Equilibrium studies}

As seen in the Fig. 5a the Freundlich model described the equilibrium adsorption process. Table 1 shown the values of the Freundlich parameters $n$ and $K_{\mathrm{F}}$ were 1.08 and $27.48 \pm 0.55 \mathrm{mg} / \mathrm{g}$, respectively. Figure $5 \mathrm{~b}$ presents the Langmuir plot for the adsorption of $\mathrm{MO}$ onto adsorbent. The straight line in the figure satisfactorily described the Langmuir model for equilibrium adsorption process. The values of the Langmuir parameters $Q_{0}$ and $b$ were $0.69 \pm 0.55 \mathrm{mg} / \mathrm{g}$ and $0.06 \mathrm{~L} / \mathrm{mg}$, respectively. Freundlich values indicated that the adsorption of MO on adsorbent was quite fast with high adsorption capacity.

\section{Sorption kinetics}

Percentage removal of $\mathrm{MO}$ at a fixed adsorbent dose was monitored with time. The kinetics of MO removal by adsorbents indicated rapid binding of MO to the sorbent during first few minutes, followed by a slow increase until a state of equilibrium in $16 \mathrm{~h}$ was reached. No change in the uptake capacity was observed with further increase in equilibration time up to $24 \mathrm{~h}$. The initial rapid phase may be due to increased number of vacant sites available at the initial stage, as a result there was an increased concentration gradient between adsorbate in solution and adsorbate on the adsorbent. Generally, when adsorption involves a surface reaction process, the initial adsorption is rapid. Then, a slower adsorption would follow as the available adsorption site gradually decreases. Kinetics (Chen et al. 2010) of sorption was modelled by the pseudo-secondorder equation models (Fig. 6). Rate equation for the pseudo-second-order model is given as equation:

$\frac{t}{Q_{t}}=\frac{t}{Q_{\mathrm{e}}}+\frac{1}{Q_{\mathrm{e}}^{2} k_{2}}$

where $k$ is the pseudo-second-order rate constant of adsorption $\left(\mathrm{g} / \mathrm{mg} / \mathrm{time}\right.$ unit) and $Q_{\mathrm{e}}$ and $Q_{t}$ were the amount of $\mathrm{MO}$ adsorbed $(\mathrm{mg} / \mathrm{g})$ at equilibrium and at time $t$, respectively. The adsorption kinetic data fitted best in pseudo-second-order model, where linear plot of $t$ versus $t / Q_{t}$ was obtained. The correlation coefficients $\left(R^{2}\right)$ and the rate constant for adsorbents are summarized in Table 1 which, suggests that adsorption is not diffusion-controlled but is chemisorption.

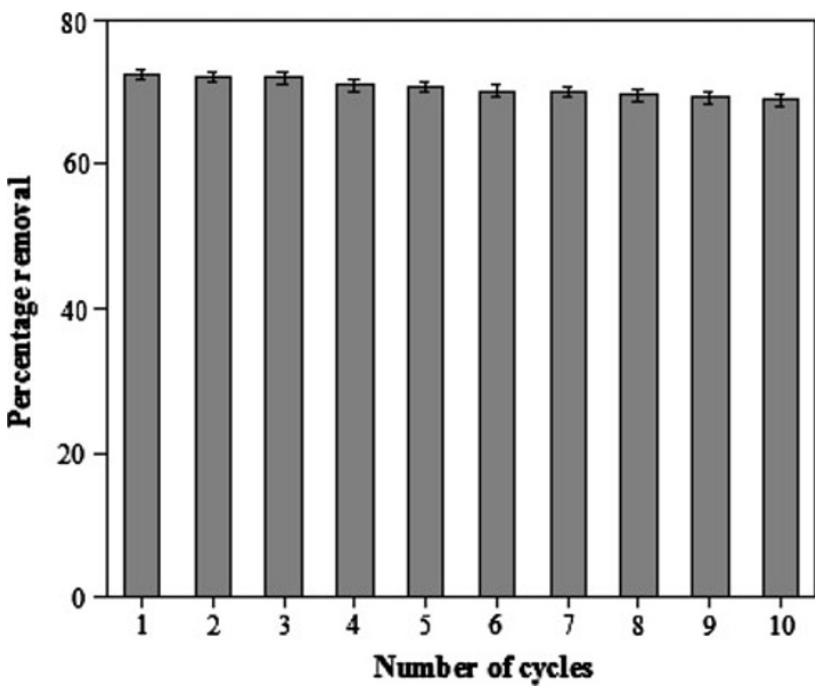

Fig. 7 MO percentage removal of AgNPs-coated AC after adsorption/desorption cycles 
Table 2 Recent reported percentage removal of MO

\begin{tabular}{|c|c|c|c|c|c|}
\hline S. No & Adsorbents & $\begin{array}{l}\text { Adsorption capacities } \\
(\mathrm{mg} / \mathrm{g})\end{array}$ & $\begin{array}{l}\text { Percentage } \\
\text { removal }(\%)\end{array}$ & Economic viability & Sources \\
\hline 1 & Mesoporous carbon material & 294.1 & 99.0 & - & $\begin{array}{l}\text { Mohammadi et al. } \\
\text { (2011) }\end{array}$ \\
\hline 2 & $\begin{array}{l}\text { Bentonite-supported nanoscale } \\
\text { zero-valent iron }\end{array}$ & - & 99.7 & - & Chen et al. (2011) \\
\hline 3 & Modified halloysite nanotubes & 94.34 & 99.0 & 4 times & Liu et al. (2012) \\
\hline 4 & $\begin{array}{l}\text { Iron(II) cross-linked chitin-based } \\
\text { gel beads }\end{array}$ & 107.5 & 82.1 & - & Li et al. (2010) \\
\hline 5 & AgNPs-coated AC & 27.48 & 72.5 & $\begin{array}{l}\text { Percentage removal almost same } \\
\text { after } 10 \text { cycles }\end{array}$ & Present work \\
\hline
\end{tabular}

\section{Desorption studies}

Desorption studies help to elucidate the nature of adsorption and to recover the valuable $\mathrm{MO}$ from aqueous solution using the adsorbent. Attempts were made to the effective desorption of MO from the spent AgNPs-coated AC using $0.05 \mathrm{~N} \mathrm{HNO}_{3}$. Adsorption and desorption data for percentage removal of MO by AgNPs-coated AC is shown in Fig. 7. It was observed that the percentage removal of AgNPs-coated AC almost same after ten adsorptiondesorption cycles. This indicates that the application of dilute solutions of $0.05 \mathrm{~N} \mathrm{HNO}_{3}$ for desorption does not change the structural characteristics of the adsorbent. This further shows that AgNPs-coated AC is a good reusable adsorbent for the removal of MO from aqueous solution.

\section{Comparison with other studies}

Table 2 shows a list of adsorbents used in wastewater treatment. Because of its great capacity to remove MO, AC is the most effective adsorbents. This capacity is mainly due to its structural characteristics and porous texture which provides a large surface area, further the chemical nature of it can be easily modified by chemical treatment to increase its adsorption properties. However, AC presents several disadvantages (Babel and Kurniawan 2003) such as expensive cost - the higher the quality, the greater is the cost, non-selective and ineffective against disperse and vat dyes. The regeneration of saturated carbon is also expensive, not straightforward, and results in loss of the adsorbent. To decrease the cost of treatment, attempts have been made to modify AC by AgNPs adsorbent. The loss of AC during recycling process by nitric acids was prevented by the coating of AgNPs over it. In addition, AgNPs provide more surface area for adsorption to occur on it and consequently this enhances the adsorption efficiency. Table 3 shows the extent of removal of the tested dye MO by different adsorbents at the optimized condition $(\mathrm{pH} \sim 7$, $27{ }^{\circ} \mathrm{C}, 16 \mathrm{~h}$ ). It is clear from the observed data that the
Table 3 Removal of MO by different adsorbents at optimized condition $\left(\mathrm{pH} \sim 7,27^{\circ} \mathrm{C}, 16 \mathrm{~h}\right)$

\begin{tabular}{lllll}
\hline S. No & $\begin{array}{l}\text { Dye } \\
(\mathrm{mg} / \mathrm{L})\end{array}$ & $\begin{array}{l}\text { AC } \\
(\%)\end{array}$ & $\begin{array}{l}\text { PVP-supported AgNPs- } \\
\text { coated AC }(\%)\end{array}$ & $\begin{array}{l}\text { PVP-supported } \\
\text { AC }(\%)\end{array}$ \\
\hline 1 & 2.0 & 50.0 & 72.5 & 60.0 \\
2 & 4.0 & 47.5 & 72.0 & 58.0 \\
3 & 6.0 & 46.6 & 71.0 & 57.3 \\
4 & 8.0 & 46.2 & 70.5 & 56.0 \\
5 & 10 & 45.0 & 70.0 & 55.1 \\
\hline
\end{tabular}

maximum degree of adsorption for different adsorbent systems, at a minimum concentration of dye tested, is in the order AC-PVP-AgNPs $(72.5 \%)>$ AC-PVP $(60.0 \%)>$ $\mathrm{AC}(50.0 \%)$.

\section{Conclusion}

Silver colloidal solutions have been synthesized rapidly in chemically green condition. In this paper, we have studied the synthesis of AgNPs from $\mathrm{AgNO}_{3}$ employing glucose as the reducing agent and PVP as the stabilizing agent. The UV-visible spectra showed that these synthesised samples have absorbance peak at $420 \mathrm{~nm}$. The average size of AgNPs is about $11 \mathrm{~nm}$ via TEM images. The newly synthesized adsorbent, AC modified with AgNPs, was applied successfully for separation of MO from aqueous solutions before they were analyzed by spectrophotometer. The contact time for the maximum adsorption required is nearly $16 \mathrm{~h}$. The data are well represented by Freundlich isotherm and Langmuir isotherm indicating favourable adsorption of MO by the adsorbent. The data on kinetic studies indicated that the adsorption kinetics of MO on AgNPs-coated AC followed the pseudo-second-order model. The adsorption efficiency of a regenerated AgNPs-coated AC adsorbent was found to be unaffected for at least ten cycles. The results of the present study conclude that AgNPs-coated $\mathrm{AC}$ is good adsorbent for removal of MO. 
Acknowledgments The authors are thankful to the Head, Prof. K.S. Patel, School of Studies in Chemistry, Pt. Ravishankar Shukla University, Raipur, India for providing laboratory facilities. Authors are also thankful to Department of Anatomy, All India Institute of Medical Sciences (AIIMS), New Delhi for providing TEM photographs. The authors wish to thank UGC-DAE Consortium for Scientific Research Indore centre for XRD analysis.

Open Access This article is distributed under the terms of the Creative Commons Attribution License which permits any use, distribution, and reproduction in any medium, provided the original author(s) and the source are credited.

\section{References}

Aksu Z (2005) Application of biosorption for the removal of organic pollutants: a review. Process Biochem 40:997-1026

Al-qodah Z (2000) Adsorption of dyes using shale oil ash. Water Res 34:4295-4303

Babel S, Kurniawan TA (2003) Low-cost adsorbents for heavy metals uptake from contaminated water: a review. J Hazard Mater 97:219-243

Bajpai AK, Rajpoot M, Mishra DD (2000) Static and kinetic studies on the adsorption behavior of sulfadiazene. Adsorption 6:349-357

Bajpai J, Shrivastava R, Bajpai AK (2004) Dynamic and equilibrium studies on adsorption of $\mathrm{Cr}(\mathrm{VI})$ ions onto binary bio-polymeric beads of cross linked alginate and gelatin. Colloids Surf 236:81-90

Banasa RC, Donne JB, Stoeckli HF (1988) Active carbon. Marcel Dekker, New York, p 27

Belhachemi M, Addoun F (2011) Comparative adsorption isotherms and modeling of methylene blue onto activated carbons. Appl Water Sci 1:111-117

Chatterjee S, Lee MW, Woo SH (2010) Adsorption of congo red by chitosan hydrogel beads impregnated with carbon nanotubes. Bioresour Technol 101:1800-1806

Chen H, Zhao J (2009) Adsorption study for removal of congo red anionic dye using organo-attapulgite. Adsorption 15:381-389

Chen DZ, Zhang JX, Chen JM (2010) Adsorption of methyl tert-butyl ether using granular activated carbon: equilibrium and kinetic analysis. Int J Environ Sci Technol 7:235-242

Chen ZX, Jin XY, Chen Z, Megharaj M, Naidu R (2011) Removal of methyl orange from aqueous solution using bentonite-supported nanoscale zero-valent iron. J Colloid Interface Sci 363:601-607

Chowdhury S, Saha PD (2012) Biosorption of methylene blue from aqueous solutions by a waste biomaterial: hen feathers. Appl Water Sci. doi:10.1007/s13201-012-0039-0

Djebbar M, Djafri F, Bouchekara M, Djafri A (2012) Adsorption of phenol on natural clay. Appl Water Sci 2:77-86

Hirai H, Chawanya H, Toshima N (1985) Colloidal palladium protected with poly(N-vinyl-2-pyrrolidone) for selective hydrogenation of cyclopentadiene. React Polym 3:127-141

Kannan N, Karrupasamy K (1998) Low cost adsorbents for the removal of phenyl acetic acid from aqueous solution. Indian $\mathrm{J}$ Environ Prot 18:683-690
Klefenz H (2004) Nanobiotechnology: from molecules to system. Eng Life Sci 4:211-218

Lakshmi D (1987) Influence of the dyestuff effluents of a textile processing unit, Cauvery river, Erode on the activity and glycogen content of brain, liver, heart and muscle tissue. M. Phil. Dissertation. Bharathiar University, Coimbatore

Lata H, Garg V, Gupta R (2008) Adsorption removal of basic dye by chemically activated parthenium biomass: equilibrium and kinetic modelling. Desalination 219:250-261

Li G, Du Y, Tao Y, Deng H, Luo X, Yang J (2010) Iron (II) crosslinked chitin-based gel beads: preparation, magnetic property and adsorption of methyl orange. Carbohydr Polym 82:706-713

Liu R, Fu K, Zhang B, Mei D, Zhang H, Liu J (2012) Removal of methyl orange by modified halloysite nanotubes. J Dispersion Sci Technol 33:711-718

Mall ID, Srivastava VC, Agarwal NK, Mishra IM (2005) Removal of congo red from aqueous solution by bagasse fly ash and activated carbon: kinetic study and equilibrium isotherm analyses. Chemosphere 61:492-501

Meshko V, Markovska L, Minchev M, Rodrigues AE (2001) Adsorption of basic dyes on granular activated carbon and natural zeolite. Water Res 35:3357-3366

Mie G (1908) Beitrage zur Optik truber Medien, speziell kolloidaler Metallosungen. Ann Phys 25:377-445

Mohammadi N, Khani H, Gupta VK, Amereh E, Agarwal S (2011) Adsorption process of methyl orange dye onto mesoporous carbon material-kinetic and thermodynamic studies. J Colloid Interface Sci 362:457-462

Nagda GK, Ghole VS (2009) Biosorption of congo red by hydrogen peroxide treated tendu waste. Iran J Environ Health Sci Eng 6:195-200

Pal J, Deb MK (2012a) Microwave green synthesis of PVP stabilized gold nanoparticles and their adsorption behaviour for methyl orange. J Exp Nanosci. doi:10.1080/17458080.2012.667160

Pal J, Deb MK (2012b) Efficient sorption of basic organic dyes from aqueous solution using green synthesized silver nanoparticles beads. J Dispers Sci Technol. doi:10.1080/01932691.2012.739939

Pal J, Deb MK (2012c) Effective removal of brilliant green dye from aqueous solution by adsorption onto biopolymer supported silver nanoparticles beads. J Indian Chem Soc 89:1-7

Pavan FA, Dias SLP, Lima EC, Benvenutti EV (2008) Removal of congo red from aqueous solution by anilinepropylsilica xerogel. Dyes Pigm 76:64-69

Reddad Z, Gerente C, Andres Y, Cloirec P (2002) Adsorption of several metal ions onto a low cost biosorbent: kinetic and equilibrium studies. Environ Sci Technol 36:2067-2073

Shah B, Tailor R, Shah A (2012) Equilibrium, kinetics, and breakthrough curve of phenol sorption on zeolitic material derived from BFA. J Dispersion Sci Technol 33:41

Talarposhti AM, Donelly T, Anderson GK (2001) Colour removal from a simulated dye wastewater using a two-phase anaerobic packed bed reactor. Water Res 35:425-432

Toshima N, Yonezawa T (1998) Bimetallic nanoparticles-novel materials for chemical and physical applications. New J Chem 22:1179-1201

Zhang R, Wang X (2007) One step synthesis of multiwalled carbon nanotube/gold nanocomposites for enhancing electrochemical response. Chem Mater 19:976-978 